\section{cAMP promotes differentiation of rodent neuronal progenitor cells}

Guilherme Lepski, ${ }^{1,2}$ Cinthia Elim Jannes, ${ }^{1}$
Guido Nikkhah ${ }^{1}$

'Department of Functional and

Stereotactic Neurosurgery, Albert

Ludwigs University, Freiburg im Breisgau;

2Department of Neurosurgery, Eberhard

Karls University, Tübingen, Germany

\section{Abstract}

Numerous studies have described neuronal differentiation of neural progenitor cells derived from fetal tissue in vitro, but the biochemical mechanisms underlying this process remain largely unknown. In the present study, the role of cAMP in promoting functional maturation of neuronal progenitor cells (NPCs) from the subventricular zone (SVZ) of rodent fetal brain was investigated. NPCs were extracted from telencephalic vesicles of E14 rat embryos and then expanded in medium containing epidermal growth factor (EGF) and basic fibroblast growth factor (bFGF). A mature neuronal fate was induced by: i) withdrawal of growth factors (basal condition); ii) addition of brain-derived neurotrophic factor (BDNF); or iii) addition of isobutylmethylxantine (IBMX). Whole cell patch clamping assessed electrophysiological properties. Immunocytochemistry for MAP2 confirmed neuronal differentiation. Quantification of neuronal cells, and determination of their electrophysiological properties, was performed in the cited experimental groups. IBMX significantly enhanced the yield of MAP2-positive neurons in the culture system (3.7-fold increase). Application of a one-week differentiation protocol under IBMX induced functional maturity. MAP2-positive cells presented large $\mathrm{Na}$ - and $\mathrm{K}$ - voltagedependent currents, fired bursts of action potentials, and exhibited spontaneous synaptic activity. Further, IBMX proved more effective than BDNF for promoting neuronal maturation, leading to higher evoked peak currents and current densities, as well as greater yields of cells firing action potentials and presenting active synaptic contacts. Our data indicates the importance of cAMP-dependent mechanisms for maturation of neuronal progenitor cells in vitro. This knowledge can enable future manipulation of neurogenesis in vivo in order to promote the intrinsic regenerative capacity of the central nervous system.

\section{Introduction}

Various different stem cell types have been considered as potential matrices to generate new neurons for central nervous system (CNS) restoration. The most important of these types include neural stem cells (NSCs), extracted from adult and fetal neuronal tissue, ${ }^{1,2}$ embryonic stem cells (ESC), from the internal layer of blastocysts, ${ }^{3,4}$ mesenchymal stem cells (MSCs), from adult bone marrow, ${ }^{5,6}$ and even somatic cells, genetically induced to an immature state, the so-called induced pluripotent stem cells (iPSC). ${ }^{7}$ We have previously demonstrated that the ability to generate functional neurons varies significantly depending on the stem cell type used. ${ }^{5}$ Among the different stem cell types, NSCs from fetal tissue have been the most intensively investigated category to date. Studies have shown that neural progenitor cells (NPCs) and NSCs from fetal brains are able to survive in the host tissue, differentiate into mature neurons, and form active synaptic contacts. ${ }^{8-10}$ Additionally, NSCs are also able to release neurotransmitters and restore functional deficits in Parkinson's disease, ${ }^{11-14}$ Huntington's disease, ${ }^{15}$ spinal cord injuries, ${ }^{16}$ stroke ${ }^{17,18}$ and motor cortical lesions. ${ }^{19}$ Although much knowledge has been gained in recent years regarding stem cell biology and plasticity, few studies have demonstrated complete electrophysiological maturation of these cells in vitro, ${ }^{10,20}$ while the mechanisms underlying this process remain largely unknown.

The key roles of cAMP and the PKA-pathway in neuronal differentiation have been described in previous studies. ${ }^{5,1-23}$ However, some controversy remains over these functions, with some authors suggesting that ATP acts preferentially on cell proliferation, serving as a negative regulator of terminal neuronal differentiation. ${ }^{24}$ cAMP on the other hand, has been shown to promote neurite elongation in NT2 embryonal carcinoma stem cells,${ }^{21}$ human neuroblastoma cell lines ${ }^{23}$ and pheochromocytoma PC12 cells, ${ }^{22}$ during neuronal differentiation. This effect is thought to occur through phosphorylation of cAMP response-element binding protein (CREB) at the Ser133 position. CREB phosphorylation induces differentiation of hippocampal progenitor cells in vitro, ${ }^{25}$ and is also believed to regulate specific phases of adult neurogenesis in the subventricular zone/olfactory bulb system in vivo, since coexpression of pCREB and bromodeoxyuridine has been demonstrated in neuroblasts within the subventricular zone. ${ }^{26}$

In order to clarify the role of cAMP in neuronal differentiation of progenitor cells derived from the rodent subventricular zone, the immunocytochemical and electrophysiological properties, after induction of a neuronal phe-
Correspondence: Guilherme Lepski, Department of Neurosurgery, Eberhard Karls University, Hoppe-Seyler-Strasse 3, 72076 Tübingen, Germany.

Tel: +49.7071.29 80325 - Fax: +49.7071.29.5245. E-mail: lepski@gmail.com

Key words: neural progenitor cells, electrophysiology, neuronal differentiation, cAMP.

Acknowledgements: the present study was sponsored by DFG (Deutsche Forschungsgemeinschaft), DAAD (Deutscher Akademischer Austauschdienst), the German Parkinson Foundation and BMBF (Bundesministerium für Bildung und Forschung, Germany).

Contributions: GL, GN, conception and design; GL, CEJ, data collection and assembly; GL, CEJ, GN, data analysis and interpretation; GL, manuscript writing; GN, financial support, administrative support, provision of study material; CEJ, GN, final manuscript approval.

Conflict of interests: the authors report no conflicts of interest.

Received for publication: 30 April 2011

Accepted for publication: 5 July 2011.

This work is licensed under a Creative Commons Attribution NonCommercial 3.0 License (CC BYNC 3.0).

(C) Copyright G. Lepski et al., 2011

Licensee PAGEPress, Italy

Stem Cell Studies 2011; 1:e9

doi:10.4081/scs.2011.eg

notype, were explored under three experimental conditions: i) basal medium, after withdrawal of growth factors; ii) brain-derived neurotrophic factor (BDNF), and iii) isobutylmethylxantine (IBMX). The yield of MAP2-positive neurons was found to increase 1.6 fold under BDNF, and 3.7 fold under IBMX. Electrophysiological recordings with patch clamp revealed significantly higher amplitudes of peak $\mathrm{Na}$ - and K-currents in cells differentiated under IBMX, as well as a higher number of cells firing action potentials and exhibiting spontaneous synaptic activity. These observations emphasize the importance of cAMP and the PKA-pathway in promoting functional maturation of neural progenitor cells.

\section{Materials and Methods}

\section{Isolation and differentiation of neural progenitor cells from E14 rat embryos}

All experiments were approved by the Research Ethics Committee of the Albert- 
Ludwig University, Freiburg. Neural progenitor cells were originally isolated from E14 Sprague-Dawley rat fetuses, as previously described. ${ }^{8}$ Pregnant females were anesthetized with an intraperitoneal injection of ketamine 10\% (Essex Pharma, Munich, Germany), their abdominal cavities opened, and uteruses removed. Fetuses were then extracted and dissected under a Leica MS5 stereomicroscope (Leica Microsystems, Heidelberg, Germany) with external light source (Leica KL1500 LCD, Leica Microsystems). The telencephalic vesicle was then dissected, immersed in Hank's balanced salt solution without $\mathrm{MgCl}_{2}$ or $\mathrm{CaCl}_{2}$ (HBSS) (Gibco, Invitrogen, Carlsbad, CA, USA), freed from meninges and surrounding vessels, then digested with trypsin $0.05 \%$ (Worthington Biochemical Corp., Lakewood, NJ, USA) and DNAse 0.05\% (Sigma-Aldrich Corp., St. Louis, $\mathrm{MO}, \mathrm{USA})$ at $37^{\circ} \mathrm{C}$ for 10 minutes. In addition, the tissue was mechanically triturated with a plastic $1 \mathrm{~mL}$ pipette to obtain a single-cell suspension. Total cell number and viability were assessed with the trypan-blue dye exclusion method. The suspension thus obtained was cultured in uncoated T75 flasks in serum-free culture medium comprising DMEM, F12, 2mM L-Glutamine, 2\% B27 serum supplement, 100 $\mathrm{U} / \mathrm{mL}$ penicillin, $100 \mu \mathrm{g} / \mathrm{mL}$ streptomycin, and $0.25 \mu \mathrm{g} / \mathrm{mL}$ amphotericin (all purchased from Gibco), $20 \mathrm{ng} / \mathrm{mL}$ basic fibroblast growth factor (bFGF, Sigma), 20ng/mL epidermal growth factor (EGF, PeproTech EC Ltd, London, UK), and $5 \mu \mathrm{g} / \mathrm{mL}$ heparin (Sigma). The flasks were incubated at $37^{\circ} \mathrm{C}, 5 \% \mathrm{CO}_{2}, 21 \% \mathrm{O}_{2}$, and $95 \%$ humidity. The medium was changed every other day, and neurospheres formed passaged by the chopping method 27 upon reaching 400 $500 \mu \mathrm{m}$ in diameter, using a McIlwainTM Tissue Chopper (ProSciTech, Thuringowa, Australia).

\section{Neuronal differentiation in vitro}

For neuronal differentiation, a previously tested protocol for human fetal neuronal progenitors was used. ${ }^{5}$ Briefly, after at least 5 passages, cell aggregates were enzymatically dissociated with AccutaseTM (PAA Laboratories, Cölbe, Germany) at $37^{\circ} \mathrm{C}$ for 12 minutes. They were then mechanically triturated with a firepolished pipette and plated at high density onto poly-L-ornithin-coated (Sigma) coverslips in differentiation medium. The medium consisted of Neurobasal (NB) (Gibco), L-glutamine (1\%, Invitrogen), $\mathrm{N} 2$ (1\%, Gibco), and PSA (1\%, Gibco), representing the basal medium condition. Alternatively, basal medium was supplemented with Neurotrophin-3 $10 \mathrm{ng} / \mathrm{mL}$ (NT3), BDNF $25 \mathrm{ng} / \mathrm{mL}$ (both from R\&D Systems, Minneapolis, MN, USA) or $0.5 \mathrm{mM} 3$ isobutyl-1-methylxantine (IBMX, Sigma), with or without $2 \%$ fetal bovine serum (Sigma). The medium was changed every other day. Cells were fixed and immunostained immediately after electrophysiological recording, which was performed on the seventh differentiation day. Cultures were fixed on the seventh differentiation day with $4 \%$ fresh PFA for $1 \mathrm{~h}$, immediately after electrophysiological recording, and were processed for immunocytochemistry.

\section{Electrophysiology}

Standard whole-cell patch clamp recording methods were used to examine the physiological properties of cultured fetal-derived neuronal cells during in vitro differentiation. Details of the recording conditions are described elsewhere. ${ }^{5,28}$ The intracellular saline solution consisted of $140 \mathrm{mM} \mathrm{KCl}, 10$ mM EGTA, 2 mM $\mathrm{MgCl}_{2}, 2 \mathrm{mM} \mathrm{Na} \mathrm{N}_{2} \mathrm{ATP}$, and 10 $\mathrm{mM}$ Hepes. The standard extracellular recording saline comprised $125 \mathrm{mM} \mathrm{NaCl}, 25 \mathrm{mM}$ $\mathrm{NaHCO}_{3}, 2.5 \mathrm{mM} \mathrm{KCl}, 1.25 \mathrm{mM} \mathrm{NaH} \mathrm{PO}_{4}$, $25 \mathrm{mM}$ Glucose, $2 \mathrm{mM} \mathrm{CaCl} 2$, and $1 \mathrm{mM} \mathrm{MgCl} 2$ (equilibrated with $95 \% \mathrm{O}_{2}, 5 \% \mathrm{CO}_{2}$ ). All recordings were made at room temperature (21$23^{\circ} \mathrm{C}$ ). Recordings were performed under visual control using an inverted microscope and phase contrast optics (Zeiss model IM35, Jena, Germany). Neuronal cells were identified based on their neuritic ramifications, which were usually visible near the cell bodies, especially in large cells. The neuronal phenotype
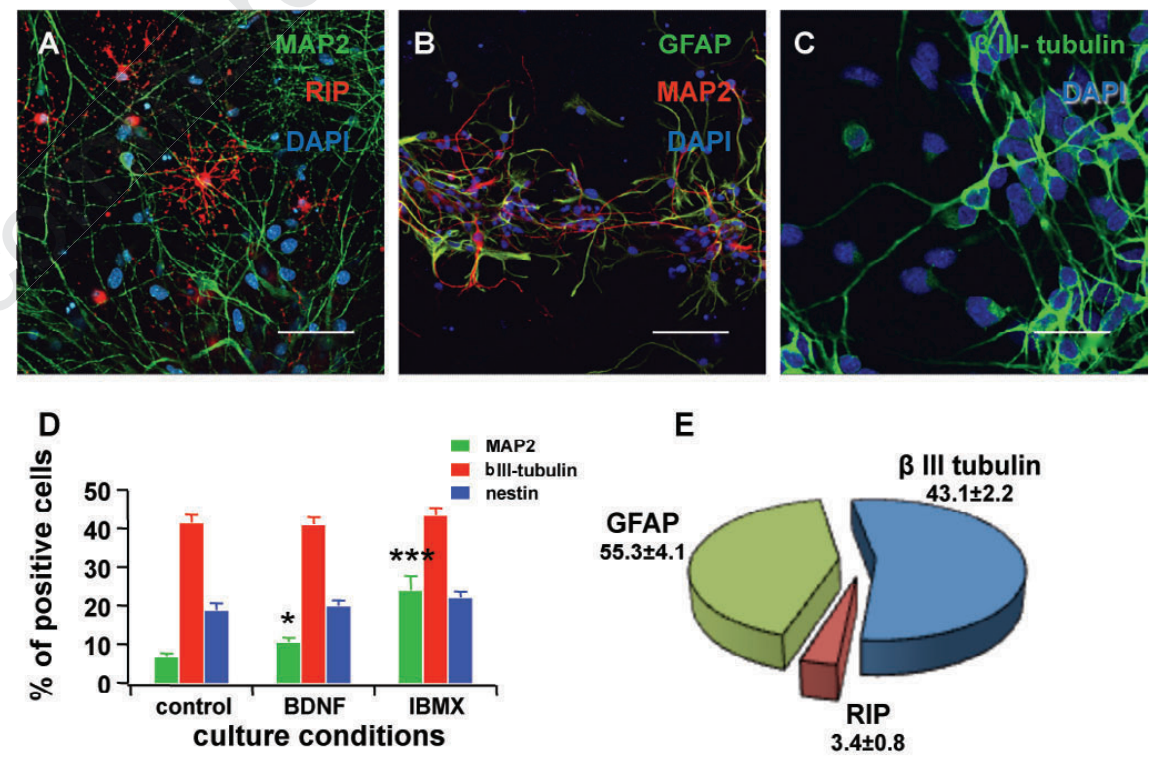

E

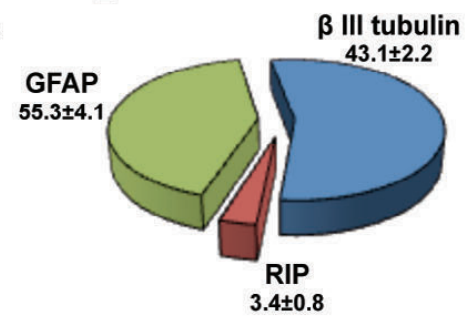

Figure 1. Multi-lineage differentiation of neuronal progenitor cells derived from rodent subventricular zone. A) Mature oligodendrocytes are stained in red with RIP, mature neurons in green with MAPs, and scale bar shown is $50 \mathrm{um}$. B) MAP-2-positive neurons are stained in red, whereas astrocytes are stained in green with the antibody anti-GFAP. The Scale bar is $80 \mathrm{um}$. C) Young neurons are shown stained in green with anti- $\square$ III-tubulin. The Scale bar is $30 \mathrm{um}$. D) The percentages of neural progenitors (nestin-positive), young neurons ( $\beta$ III-tubulin-positive), and mature neurons (MAP2-positive), were determined under the three experimental conditions, namely, in the control situation without growth factors, in BDNF and finally, in IBMX. Note the larger proportion of mature neuronal cells under IBMX, with no significant difference in the number of immature cells. ${ }^{*} \mathbf{P}<0.05 ;{ }^{* *} \mathbf{P}<0.01 ;{ }^{* * *} \mathbf{P}<0.001$. E) Fate distribution in cells cultured under IBMX for 7 days. It is important to note that neuronal precursors also stain positively for GFAP. 
points at the maximal outward current value. The leakage and capacitive currents were subtracted on-line using a P/-4 protocol as described previously. ${ }^{29}$ Current densities were calculated by dividing peak current by cell capacitance. The activation curves were obtained from the respective peak currents assuming ohmic behavior. The activation of $\mathrm{Na}^{+}$- and $\mathrm{K}^{+}$-currents (I-V relationship) was fitted with a Boltzmann equation, multiplied by a driving force considering the reversal potential for $\mathrm{K}^{+}$and for $\mathrm{Na}^{+}$, calculated as $-95 \mathrm{mV}$ and $80 \mathrm{mV}$, respectively, according to the Nernst equation with the solutions used. ${ }^{5}$

In current clamp mode, action potentials were elicited by clamping the cells at $-80 \mathrm{mV}$ and applying 10 voltage pulses, starting from 20 and increasing to $+70 \mathrm{pA}$ at $10 \mathrm{pA}$ increments. During the recording session, the cells were filled with biocytin (Molecular Probes, $1 \mathrm{mg} / \mathrm{mL}$ ). All patched cells were fixed and double-stained for biocytin and MAP2, for phenotypic characterization.

\section{Fixation and immunostaining}

Immunostaining of cell cultures was carried out as described elsewhere. ${ }^{30}$ Briefly, cultures were fixed in fresh 4\% PFA (pH 7.2) for one hour, incubated in a blocking solution containing 4\% goat serum (Sigma) and 0.1\% Triton X100 (Sigma), then incubated with antiMAP2ab (1:200, mouse monoclonal, Millipore/ Chemicon Corp., Billerica, MA, USA) and antisynaptophysin (1:1000, mouse monoclonal, Millipore/Chemicon) overnight at $4^{\circ} \mathrm{C}$. After washing, cells were incubated in secondary antibodies and 4.6-diamidino-2-phenylindole dihydrochloride (DAPI, 1:10,000, Sigma). Biocytin staining after electrophysiological recording was revealed by fluorescein-avidin D (1:500, Vector Labs, Burlingame, CA, USA). The secondary antibodies used were Alexa Fluor 488 and 594-goat anti-mouse (1:150, Molecular Probes). Fixed tissue, without primary and secondary antibodies, served as negative controls.

\section{Confocal microscopy and cell quan- tification}

Images were obtained with a Leica TCS SP2 confocal system (405 nm diode, Ar/ArKr, HeNe $543 / 594$ lasers) using the $20 \mathrm{x} / 0.7$ or $63 \mathrm{x} / 1.2$ objectives, and digitized at $2048 \times 2048$ pixels. For quantification, ten consecutive images across the horizontal diameter of each coverslip were systematically scanned from left to the right for each culture condition. Cells positive for a specific marker were counted relative to the total number of DAPI-stained nuclei using ViewFinder 2.1 software (ERDAS Imagine, Leica Geosystems Geospatial Imaging, Norcross, GA, USA). Experiments were performed in triplicate, and counting was performed in a double-blind manner, using cultures from which some cells had been previously patched.

\section{Statistical analysis}

The Mann-Whitney U-non-parametric Test was used to compare means between the groups, since a normal distribution could not be assumed. All data are reported as mean \pm s.e.m., with significance level $(\mathrm{P})$ indicated as follows: ${ }^{*} \mathrm{P}<0.05 ; \quad * * \mathrm{P}<0.01$; $* * * \mathrm{P}<0.001$.

The SPSS 13.0 Software package (IBM Corporation, Somer, NY, USA) was used for statistical computations. Graphs were constructed with Igor 5.02 (WaveMetrics).
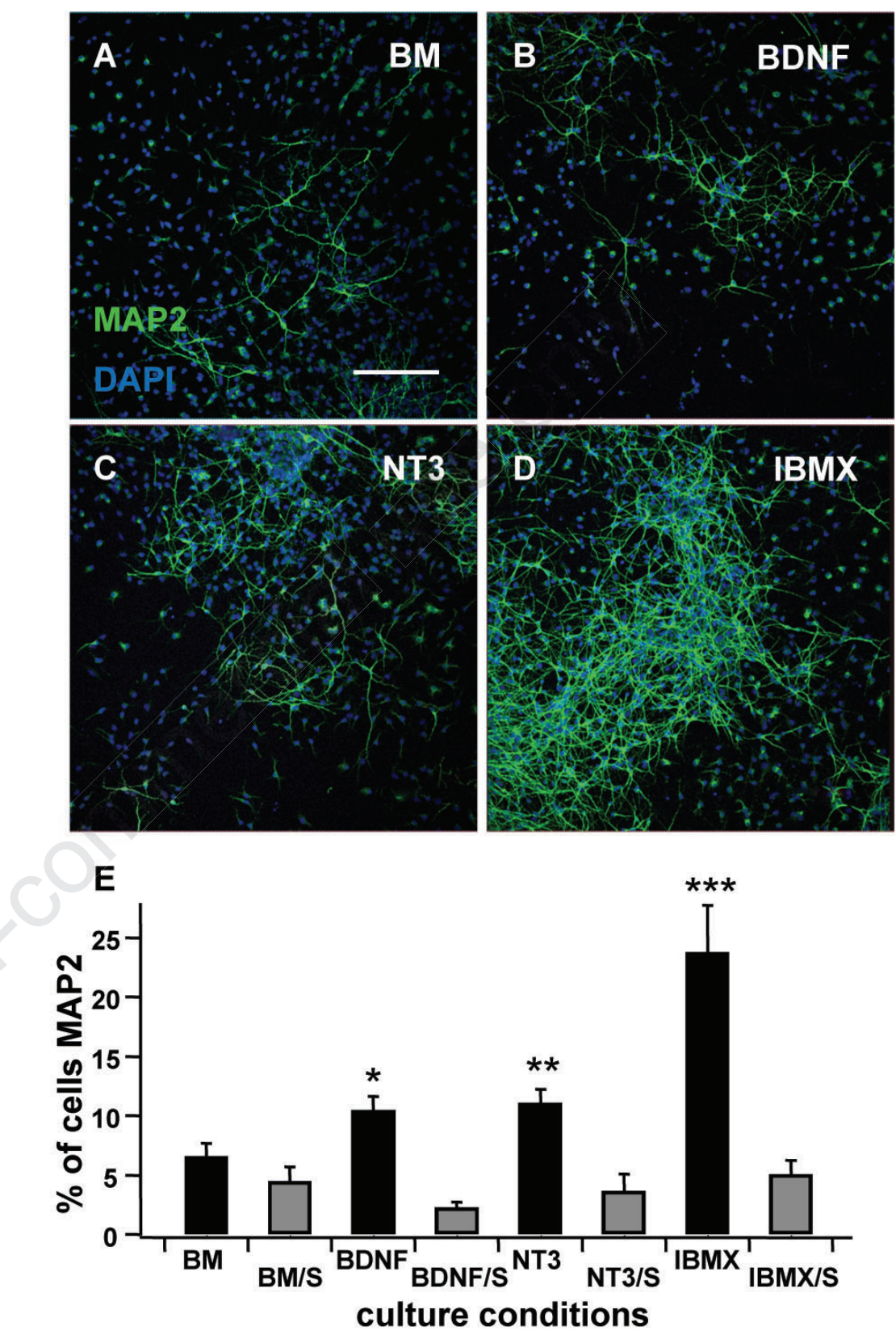

Figure 2. cAMP enhances the yield of MAP2-positive neurons in culture. A-D) Confocal pictures of differentiated cells derived from E14.5 telencephalic tissue, cultured under various conditions after 7 days in vitro. Cell nuclei are stained with DAPI in blue; green represents MAP2-Alexa Fluor 488. Scale bars A-D are $150 \mathrm{um}$. E) Quantification of MAP2 positivity, expressed in percentage of positive cells in relation to total cells. Note that NT3 and BDNF, when added to basal medium (BM), promote an increase in the yield of neuronal cells of the same magnitude. IBMX has a more marked effect however, causing a 5-fold increase in number of neuronal cells. Interestingly, the addition of serum to the culture system reduces the percentage of neuronal cells, possibly by inducing the growth of immature cell types. ${ }^{*} \mathrm{P}<0.05$; ${ }^{* *} \mathrm{P}<0.01$; ${ }^{* * *} \mathrm{P}<0.001$. 


\section{Results}

\section{cAMP enhances yield of MAP2-}

\section{positive neurons in culture}

The expression of MAP2 in differentiated cells was first investigated under the three experimental conditions for 7 days in vitro. After withdrawal of growth factors, $6.38 \pm .18 \%$ of the cells expressed MAP2 in basal medium. This number increased to $10.26 \pm 1.26(\mathrm{P}<0.05)$ under BDNF, and similarly to $10.85 \pm 1.28$ in NT3 $(\mathrm{P}<0.05)$. A more pronounced increase in the neuronal cell percentage was observed under IBMX (23.58 $\pm 4.07, \mathrm{P}<0.001)$. Additionally, IBMX was able to induce differentiation of both oligodendrocytes (RIP-positive) and astrocytes (GFAP-positive) (Figure 1A-C,E). Notably, the proportion of immature neural progenitors (nestin-positive) and young neuronal cells ( $\beta$ III-tubulin) did not differ significantly across the experimental groups (Figure 1D). Interestingly, when fetal bovine serum was added to the differentiation medium, the effect of BDNF and IBMX was masked. Specifically, the yield of MAP2-cells was $4.28 \pm 1.30$ in basal medium, $2.09 \pm 0.56$ in BDNF, $3.48 \pm 1.50$ in NT3 and finally, $4.87 \pm 1.28$ in IBMX (Figure 2). These data indicate the importance of BDNF and NT3 for neuronal differentiation, and point to a more significant contribution of IBMX.

\section{cAMP promotes functional matura-} tion of neural precursor cells within seven days in vitro

Patch clamp recordings of electrophysiological events revealed that cAMP was able to induce full maturity in a 7-day time window. On the $7^{\text {th }}$ differentiation day, large K-currents $(6.4 \pm 1.5 \mathrm{nA})$ and Na-currents $(2.5 \pm 0.6 \mathrm{nA})$ were recordable. Accordingly, K- and Na-current densities, which correspond to the density of ionic channels on cell surfaces, were $861 \pm 193 \mathrm{pA} / \mathrm{pF}$ and $383 \pm 109 \mathrm{pA} / \mathrm{pF}$, respectively. At this stage, $50 \%$ of the cells fired action potentials, and $16.7 \%$ displayed spontaneous synaptic activity. Cells with action potentials fired at $21.6 \pm 8.3 \mathrm{~Hz}$, and the peak amplitude was measured as $49 \pm 14 \mathrm{mV}$. Figure 3 illustrates a high proportion of MAP2-positive cells (panel A), as well as the co-staining of MAP2 and synaptophysin in the dendrites of neuronal cells (panel B). During recording sessions, cells were filled with biocytin and then stained for MAP2, thus confirming neuronal fate. Figure 3C illustrates two recorded cells with long and ramified neuritic extensions. Inward and outward currents are represented in Figure 3D, and voltage-dependent activation is depicted in Figure 3E. Bursts of action potentials and spontaneous synaptic activity were also observed (Figure 3F and 3G, respectively).
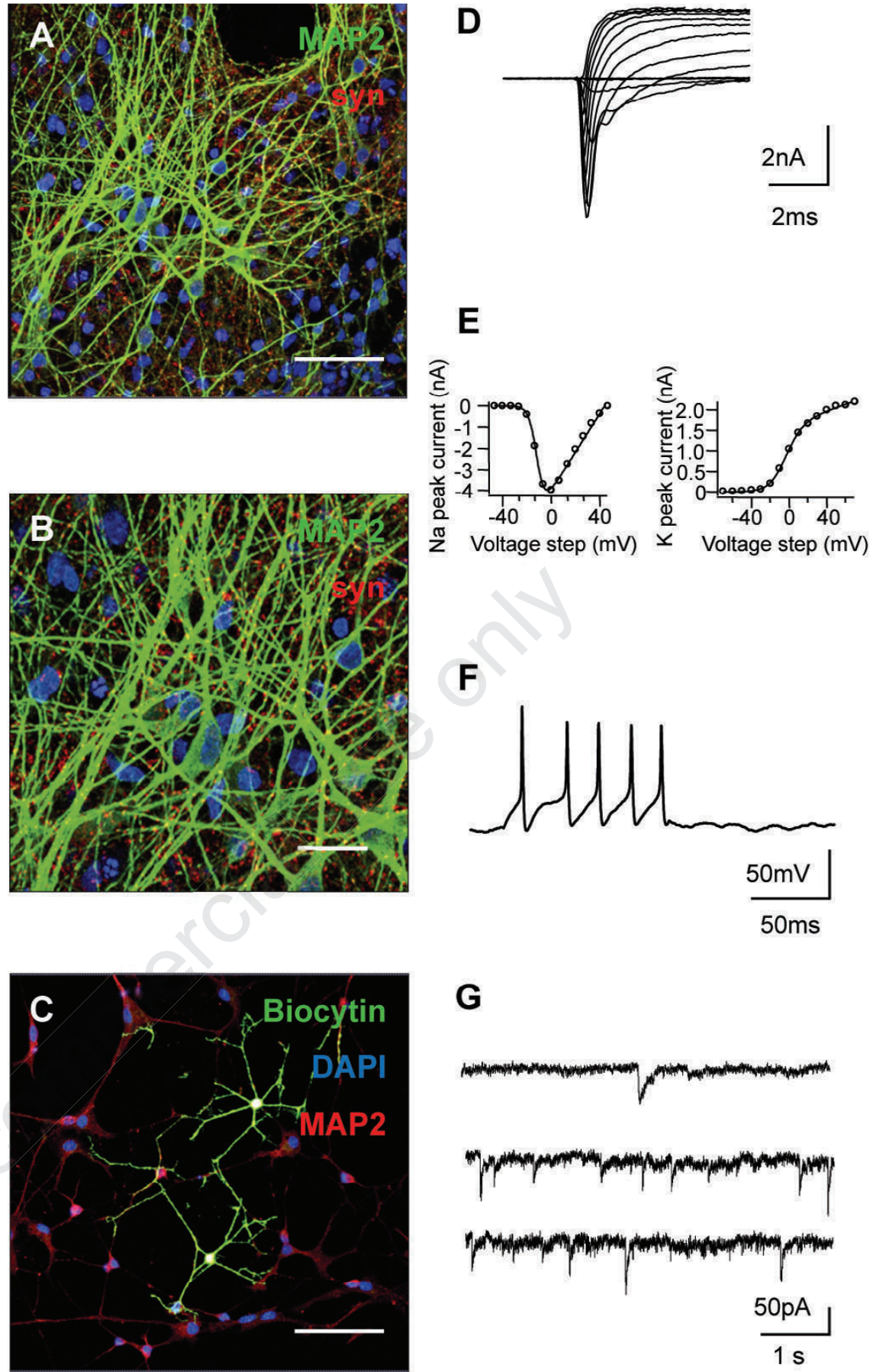

G

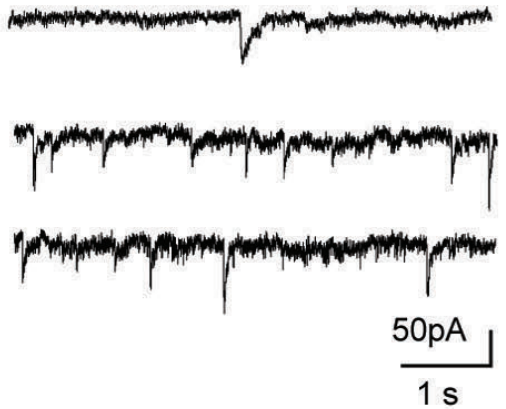

Figure 3. cAMP promotes functional maturation of neural precursor cells within seven days in vitro. A-C) Confocal pictures of differentiated cells, cultured under IBMX in basal medium for 7 days. A-B) Green represents mature neuronal cells stained with MAP2, revealed with Alexa-Fluor488, whereas red represents pre-synaptic vesicles stained with synaptophysin-Alexa594. Note some pre-synaptic vesicles along MAP2-positive dendrites of mature cells; some vesicles can be seen in non-stained dendrites, probably from immature cells. C) Patched cells were filled with biocytin (green, FITC) during electrophysiological recording, allowing subsequent confirmation of neuronal fate, since positivity for MAP2 (red) was demonstrated. Scale bars are as follows: A:50 um, B:25 um, C:70 um. D) Currents evoked in voltage clamp mode, after application of 15 voltage pulses from a holding potential of $-80 \mathrm{mV}$, at $10 \mathrm{mV}$ increments; capacitive and leakage currents were subtracted using a $\mathrm{p} /-4$ protocol (see text). E) Voltage-dependent activation of sodium (left) and potassium (right) currents, i.e. I-V plots. Curve fitting with a theoretical model predicted by a non-raised Boltzmann function multiplied by a driving force, considering the Nernst potential for each ion with the solutions used (for more details see text and references). F) Bursts of action potentials, evoked after application of $20 \mathrm{pA}$ for $100 \mathrm{~ms}$. G) Spontaneous synaptic currents recorded in the same cell illustrated in D-F. 
Isobutylmethylxantine is more effective than brain-derived neurotrophic factor for inducing functional maturity

Analysis of the electrophysiological properties of cells differentiated in basal medium, BDNF, and IBMX, revealed strong evidence of increased maturity in the IBMX-group (Figure 4). First, the membrane time constant was significantly lower $(28.1 \pm 7.1$ for IBMX, $26.9 \pm 8.9$ for BDNF, and $40.2 \pm 15.3$ for basal medium, $\mathrm{P}$ IBMX x BM <0.01). Second, current peaks were considerably higher for sodium, measuring 2.5 $\pm 0.6 \mathrm{nA}$ in the IBMX-group $(\mathrm{P}<0.001)$, $511 \pm 138 \mathrm{pA}$ in the BDNF-group $(\mathrm{P}<0.01)$, and $653 \pm 50 \mathrm{pA}$ in the basal medium group. Similarly, amplitudes of K-peak currents were considerably higher in the IBMX-group, although this difference did not reach statistical significance (Figure 4A). Current densities are reliable indicators of ionic channel density on cell surfaces. Both Na and K- current densities were significantly higher in the IBMXgroup, as shown in Figure 4B and 4D $(\mathrm{P}<0.001$ for $\mathrm{Na}$ and $\mathrm{K}$ ). Moreover, a higher yield of neuronal cells in the IBMX group fired action potentials (IBMX 50\%, BDNF 21.7\%, BM 13.5\%) and exhibited spontaneous synaptic activity (16.7\%, $4.3 \%$ and 0 , respectively).

\section{Discussion}

Clonal-expanded neuronal precursor cells from the subventricular zone represent a viable option for neural restoration and offer several advantages, namely: i) clonal expansion allows the obtention of a large number of cells from a single fetal brain, thereby resolving the dilemma over limited availability of fetal tissue for transplantation purposes; ii) clonal expansion does not prevent acquirement of a mature neuronal fate, ${ }^{30}$ despite reduced neurogenic potential due to aging; iii) clonal-expanded neuronal precursors from the SVZ are able to develop into electrophysiologically active neurons both in vitro ${ }^{28}$ and in vivo, after transplantation. ${ }^{8}$ However, the assumption that other stem cell types have similar neurogenic potential as NPCs from the SVZ requires further experimental confirmation. Comparisons of adult mesenchymal and neuronal stem cells have clearly demonstrated the limited neurogenic potential of the former type. ${ }^{5}$ Another relevant issue is biological safety, especially concerning possible clinical applications. In this regard, a physiological rule can be applied: the more immature the stem cell, the higher the chances of malignant degeneration. This is because the proliferative potential is high and difficult to control. ${ }^{31}$ In fact, ESCs have been shown to induce the for- mation of malignant teratomas in up to $25 \%$ of implanted animals. ${ }^{4,32}$

Various studies have demonstrated the importance of the cAMP and PKA-pathway in neuronal differentiation. ${ }^{21-23,33} \mathrm{P} 1$ receptors are activated by adenosine and act through $\mathrm{G}$ protein. $\mathrm{P} 2$ receptors on the other hand, are activated by ATP and can be metabotropic, G-pro-
A
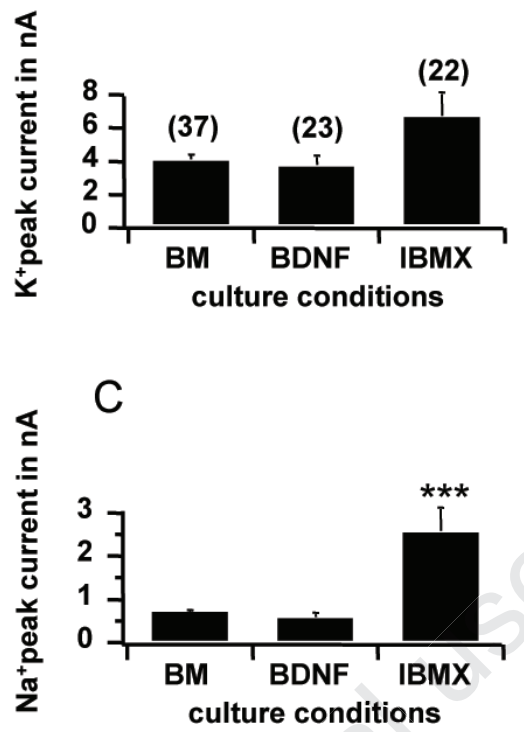

E

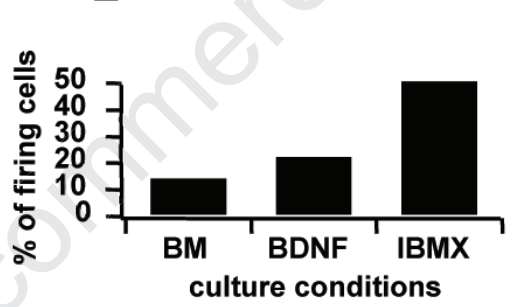

G

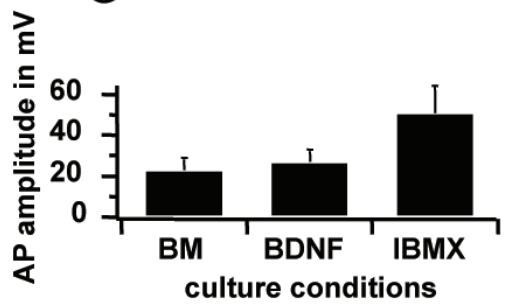

tein-coupled (P2Y), or ionotropic, causing transient influx of $\mathrm{Ca}^{2+}(\mathrm{P} 2 \mathrm{X}) .{ }^{34}$ In cells, both second messengers $\mathrm{Ca}^{2+}$ and cAMP can induce phosphorylation of CREB at Ser133 through protein kinases. CREB is a known transcription factor expressed during neurogenesis in the rostral migratory stream. ${ }^{26}$ In vitro, CREB was shown to induce differentiation of hippocampal
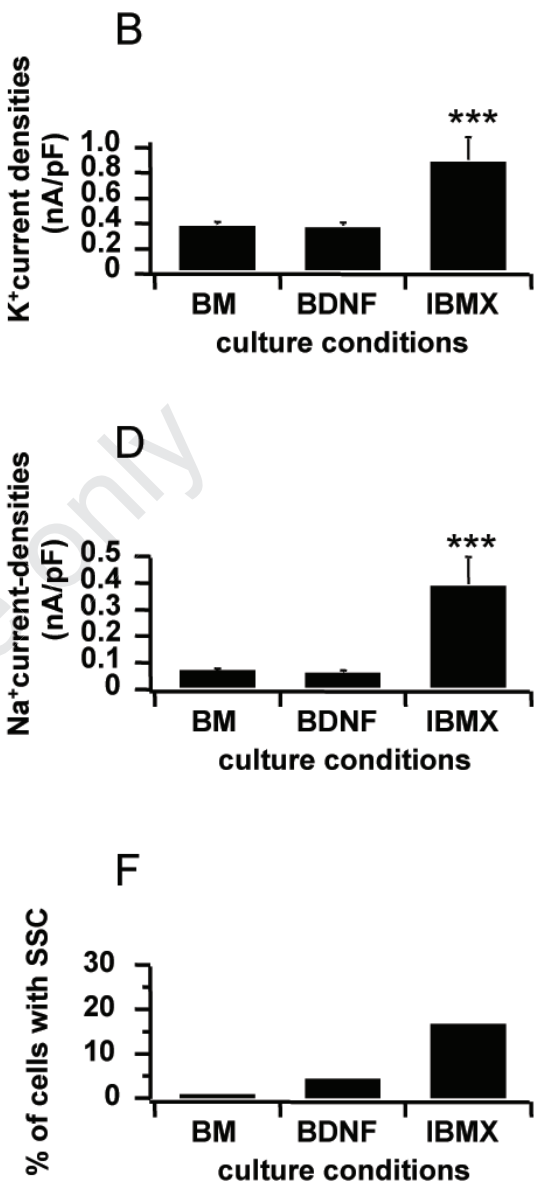

Figure 4. Isobutylmethylxantine was more effective than brain-derived neurotrophic factor for inducing electrophysiological maturity using a seven-day differentiation protocol. A) Potassium peak currents recorded in cells differentiated in basal medium, basal medium supplemented with BDNF, and basal medium with IBMX. The cell numbers shown in parenthesis above the bars in Graph $A$ are valid for all graphs. Error bars represent s.e.m. Significance values are indicated as follows: ${ }^{*} \mathrm{P}<0.05$; ${ }^{* *} \mathrm{P}<0.01 ;{ }^{* * *} \mathrm{P}<0.001$. A larger mean value was observed in the IBMX-group, albeit without reaching statistical significance. B) Potassium current densities were calculated as indicated in the text, and in this case cells cultivated under IBMX produced significantly higher currents. Similarly, considerably higher sodium-peak currents (C) and sodium current densities (D) were observed in cells under IBMX. A higher yield of cells differentiated in medium containing IBMX exhibited action potentials (E) and spontaneous synaptic currents (F). Firing frequency (G) and amplitude of action potentials $(\mathrm{H})$ were slightly higher in the IBMXgroup, although without reaching statistical significance (for $\alpha$ error of $5 \%$ ). 
progenitor cells. ${ }^{35}$ The cAMP is also involved in neurite elongation in a variety of immature cells, such as NT2 carcinoma stem cells, ${ }^{21} \mathrm{SH}$ SY5Y human neuroblastoma cells, ${ }^{23}$ and pheochromocytoma PC12 cells. ${ }^{22}$ cAMP is believed to act synergistically with nerve growth factor (NGF) and activate a group of different genes involved in neuronal differentiation, calcium transmission, Na-channel expression, and neurite outgrowth. ${ }^{22}$ The expression of high levels of $\mathrm{Na}$-channels has recently been shown to be particularly important for induction of electrical maturity. ${ }^{28}$ Our data confirm the neurogenic effect of increased cAMP in cultures of NPCs derived from rodent SVZ. However, we failed to observe any significant effect on proliferation of immature cells, and observed a 3.7 -fold increase in the percentage of neuronal cells under IBMX compared to controls. Taken together, these data support the idea that cAMP acts by shortening the differentiation process. This hypothesis was corroborated by the results of the electrophysiological analysis, which revealed significantly higher amplitudes of voltage-gated currents in neuronal cells under IBMX, along with a higher proportion of cells firing action potentials and presenting spontaneous synaptic currents. BDNF is also another important growth factor, which is active during neurogenesis. BDNF acts through TrkB receptors (tyrosine kinase receptor B) and causes differentiation of neuronal progenitor cells both in vitro30 and in vivo. ${ }^{36}$ It also induces expression of $\mathrm{Na}^{+}$and $\mathrm{K}^{+}$channels, ${ }^{37}$ which are essential for electrophysiological maturation. Furthermore, BDNF seems to be especially important in promoting synaptic maturation and plasticity, probably by inducing $\mathrm{Ca}^{2+}$-influx through NMDA-receptors. ${ }^{38,39}$ NT-3 is structurally related to BDNF and binds to TrkA receptors, also promoting neuronal differentiation. ${ }^{40}$ In the damaged nervous system, glial cells outside the neurogenic areas acquire or reactivate stem cell properties and can migrate to the injured site, where they contribute to local repair. ${ }^{41}$ However, the brain environment in vivo does not allow neurogenic niches after injury, and the migrated precursors thus tend to differentiate into glial cells. ${ }^{42-47}$ Unveiling the molecular pathways involved in neurogenesis might enable recruitment of local stem cells which can subsequently be induced to neurodifferentiate and repopulate damaged area with new neurons. In a demonstration of this concept, intra-spinal infusion of bFGF was shown to promote functional recovery in spinal cord injury in rats. ${ }^{48}$ Similarly, intraventricular delivery of bFGF promoted neuronal differentiation and cognitive improvement after traumatic brain injury in rats. ${ }^{49}$ Evidence pointing to the importance of cAMP in functional maturation of NPC from the SVZ opens up new perspectives of investigation in the field of Stem Cell Biology.

\section{References}

1. Reynolds BA, Weiss S. Generation of neurons and astrocytes from isolated cells of the adult mammalian central nervous system. Science 1992;255:1707-10.

2. Svendsen CN, Fawcett JW, Bentlage C, Dunnett SB. Increased survival of rat EGFgenerated CNS precursor cells using B27 supplemented medium. Exp Brain Res 1995;102:407-14.

3. Wernig M, Benninger F, Schmandt T, et al. Functional integration of embryonic stem cell-derived neurons in vivo. J Neurosci 2004;24:5258-68.

4. Kim JH, Auerbach JM, Rodriguez-Gomez $\mathrm{JA}$, et al. Dopamine neurons derived from embryonic stem cells function in an animal model of Parkinson's disease. Nature 2002;418:50-6.

5. Lepski G, Jannes CE, Maciaczyk J, et al. Limited $\mathrm{Ca} 2+$ and PKA-pathway dependent neurogenic differentiation of human adult mesenchymal stem cells as compared to fetal neuronal stem cells. Exp Cell Res 2010;316:216-31.

6. Lepski G, Jannes CE, Strauss B, et al. Survival and neuronal differentiation of mesenchymal stem cells transplanted into the rodent brain are dependent upon microenvironment. Tissue Eng Part A 2010;16:2769-82.

7. Wernig M, Zhao JP, Pruszak J, et al. Neurons derived from reprogrammed fibroblasts functionally integrate into the fetal brain and improve symptoms of rats with Parkinson's disease. Proc Natl Acad Sci U S A 2008;105:5856-61.

8. Lepski G, Jannes CE, Wessolleck J, et al. Equivalent neurogenic potential of wildtype and GFP-labeled fetal-derived neural progenitor cells before and after transplantation into the rodent hippocampus. Transplantation 2011;91:390-7.

9. Uchida K, Momiyama T, Okano H, et al. Potential functional neural repair with grafted neural stem cells of early embryonic neuroepithelial origin. Neurosci Res 2005;52:276-86.

10. Sørensen AT, Thompson L, Kirik D, et al. Functional properties and synaptic integration of genetically labelled dopaminergic neurons in intrastriatal grafts. Eur $\mathrm{J}$ Neurosci 2005;21:2793-9.

11. Freed CR, Greene PE, Breeze RE, et al. Transplantation of embryonic dopamine neurons for severe Parkinson's disease. N Engl J Med 2001;344:710-9.

12. Kordower JH, Goetz CG, Freeman TB, et al. Dopaminergic transplants in patients with Parkinson's disease: neuroanatomical correlates of clinical recovery. Exp Neurol 1997;144:41-6.
13. Lindvall $\mathrm{O}$, Brundin $\mathrm{P}$, Widner $\mathrm{H}$, et al. Grafts of fetal dopamine neurons survive and improve motor function in Parkinson's disease. Science 1990;247:574-7.

14. Mendez I, Sanchez-Pernaute R, Cooper 0, et al. Cell type analysis of functional fetal dopamine cell suspension transplants in the striatum and substantia nigra of patients with Parkinson's disease. Brain 2005;128:1498-510.

15. Capetian P, Knoth R, Maciaczyk J, et al. Histological findings on fetal striatal grafts in a Huntington's disease patient early after transplantation. Neuroscience 2009; 160:661-75.

16. Bohl D, Liu S, Blanchard S, et al. Directed evolution of motor neurons from genetically engineered neural precursors. Stem Cells 2008;26:2564-75.

17. Bliss TM, Kelly S, Shah AK, et al. Transplantation of hNT neurons into the ischemic cortex: cell survival and effect on sensorimotor behavior 1. J Neurosci Res 2006;83:1004-14.

18. Kelly S, Bliss TM, Shah AK, et al. Transplanted human fetal neural stem cells survive, migrate, and differentiate in ischemic rat cerebral cortex 2. Proc Natl Acad Sci USA 2004;101:11839-44.

19. Gaillard A, Prestoz L, Dumartin B, et al. Reestablishment of damaged adult motor pathways by grafted embryonic cortical neurons. Nat Neurosci 2007;10:1294-9.

20. Auerbach JM, Eiden MV, McKay RD. Transplanted CNS stem cells form functional synapses in vivo. Eur $\mathrm{J}$ Neurosci 2000;12:1696-704.

21. Tegenge MA, Roloff F, Bicker G. Rapid differentiation of human embryonal carcinoma stem cells (NT2) into neurons for neurite outgrowth analysis. Cell Mol Neurobiol 2011;31:635-43.

22. Ng YP, Wu Z, Wise H, et al. Differential and synergistic effect of nerve growth factor and cAMP on the regulation of early response genes during neuronal differentiation. Neurosignals 2009;17:111-20.

23. Sanchez S, Jimenez C, Carrera AC, et al. A cAMP-activated pathway, including PKA and PI3K, regulates neuronal differentiation. Neurochem Int 2004;44:231-42.

24. Lin JH, Takano T, Arcuino G, et al. Purinergic signaling regulates neural progenitor cell expansion and neurogenesis. Dev Biol 2007;302:356-66.

25. Yang EJ, Yoon JH, Min DS, et al. LIM kinase 1 activates cAMP-responsive element-binding protein during the neuronal differentiation of immortalized hippocampal progenitor cells. J Biol Chem 2004;279: 8903-10.

26. Giachino C, De MS, Giampietro C, et al. cAMP response element-binding protein regulates differentiation and survival of 
newborn neurons in the olfactory bulb. $\mathrm{J}$ Neurosci 2005;25:10105-18.

27. Svendsen CN, ter Borg MG, Armstrong RJ, et al. A new method for the rapid and long term growth of human neural precursor cells. J Neurosci Methods 1998;85:141-52.

28. Lepski G, Maciaczyk J, Jannes CE, et al. Delayed functional maturation of human neuronal progenitor cells in vitro. Mol Cell Neurosci 2011;47:36-44.

29. Bischofberger J, Geiger JR, Jonas P. Timing and efficacy of $\mathrm{Ca} 2+$ channel activation in hippocampal mossy fiber boutons. J Neurosci 2002;22:10593-602.

30. Maciaczyk J, Singec I, Maciaczyk D, Nikkhah G. Combined use of BDNF, ascorbic acid, low oxygen, and prolonged differentiation time generates tyrosine hydroxylase-expressing neurons after long-term in vitro expansion of human fetal midbrain precursor cells. Exp Neurol 2008;213: $354-62$.

31. Huang J, Wang F, Okuka M, et al. Association of telomere length with authentic pluripotency of ES/iPS cells. Cell Res 2011;21:779-92.

32. Aleckovic M and Simon C. Is teratoma formation in stem cell research a characterization tool or a window to developmental biology? Reprod Biomed Online 2008;17: 270-80.

33. Kao HT, Song HJ, Porton B, et al. A protein kinase A-dependent molecular switch in synapsins regulates neurite outgrowth. Nat Neurosci 2002;5:431-7.

34. Majumder P, Trujillo CA, Lopes CG, et al. New insights into purinergic receptor signaling in neuronal differentiation, neuro- protection, and brain disorders. Purinergic Signal 2007;3:317-31.

35. Yang EJ, Yoon JH, Min DS, Chung KC. LIM kinase 1 activates cAMP-responsive element-binding protein during the neuronal differentiation of immortalized hippocampal progenitor cells. J Biol Chem 2004;279: 8903-10.

36. Chen K, Henry RA, Hughes SM, Connor B. Creating a neurogenic environment: the role of BDNF and FGF2. Mol Cell Neurosci 2007;36:108-20.

37. Leng J, Jiang L, Chen H, Zhang X. Brainderived neurotrophic factor and electrophysiological properties of voltage-gated ion channels during neuronal stem cell development. Brain Res 2009;1272:14-24.

38. Babu H, Ramirez-Rodriguez G, Fabel K, et al. Synaptic network activity induces neuronal differentiation of adult hippocampal precursor cells through BDNF signaling. Front Neurosci 2009;3:49.

39. Levine ES, Dreyfus CF, Black IB, Plummer MR. Brain-derived neurotrophic factor rapidly enhances synaptic transmission in hippocampal neurons via postsynaptic tyrosine kinase receptors. Proc Natl Acad Sci U S A 1995;92:8074-7.

40. Yoo M, Joung I, Han AM, et al. Distinct effect of neurotrophins delivered simultaneously by an adenoviral vector on neurite outgrowth of neural precursor cells from different regions of the brain. J Microbiol Biotechnol 2007;17:2033-41.

41. Robel S, Berninger B, Gotz M. The stem cell potential of glia: lessons from reactive gliosis. Nat Rev Neurosci 2011;12:88-104.

42. Barnabé-Heider F, Goritz C, Sabelstrom H, et al. Origin of new glial cells in intact and injured adult spinal cord. Cell Stem Cell 2010;7:470-82.

43. Buffo A, Rite I, Tripathi P, et al. Origin and progeny of reactive gliosis: A source of multipotent cells in the injured brain. Proc Natl Acad Sci U S A 2008;105:3581-6.

44. Dimou L, Simon C, Kirchhoff F, et al. Progeny of Olig2-expressing progenitors in the gray and white matter of the adult mouse cerebral cortex. J Neurosci 2008;28: 10434-42.

45. Kang SH, Fukaya M, Yang JK, et al. NG2+ CNS glial progenitors remain committed to the oligodendrocyte lineage in postnatal life and following neurodegeneration. Neuron 2010;68:668-81.

46. Tatsumi K, Takebayashi H, Manabe T, et al. Genetic fate mapping of Olig2 progenitors in the injured adult cerebral cortex reveals preferential differentiation into astrocytes. J Neurosci Res 2008;86:3494-502.

47. Nakagomi T, Taguchi A, Fujimori Y, et al. Isolation and characterization of neural stem/progenitor cells from post-stroke cerebral cortex in mice. Eur $\mathrm{J}$ Neurosci 2009;29:1842-52.

48. Rabchevsky AG, Fugaccia I, Turner AF, et al. Basic fibroblast growth factor (bFGF) enhances functional recovery following severe spinal cord injury to the rat. Exp Neurol 2000;164:280-91.

49. Sun D, Bullock MR, McGinn MJ, et al. Basic fibroblast growth factor-enhanced neurogenesis contributes to cognitive recovery in rats following traumatic brain injury. Exp Neurol 2009;216:56-65. 